\title{
KERAGAMAN MORFOLOGI MODIFIKASI BATANG (CAULIS) DI KECAMATAN LUBUKLINGGAU TIMUR I, LUBUKLINGGAU
}

Reny Dwi Riastuti ${ }^{*}$, Nopa Nopiyanti², Yuli Febrianti ${ }^{3}$

${ }^{1}$ STKIP-PGRI Lubuklinggau, Jl. Mayor Toha Kel. Air Kuti, Lubuklinggau 31626, Indonesia

*Corresponding author, e-mail: renydwiriastuti09@gmail.com

\section{ABSTRACT}

The purpose of this research that has been carried out is to analyze the diversity of morphology of stem modification (caulis) in the Sub-District of East Lubuklinggau I. The technique of collecting the data that has been carried out by observation. The data obtained from the study were analyzed descriptively qualitatively and quantitatively. The results of the study have found 29 species, namely 12 species that have cirrhus, namely Pisum sativum, Psophocarpus tetragonolobus, Vigna sinensis, Ipomoea batatas, Piper betle, Cucumis sativus, Momordica charantia, Cucurbita moschata, Passiflora quadrangularis, Cylea barbata, Vitis vinifera, Mikania micrantha, 7 species that have rhizomes, namely Cyperus rotundus, Etlingera hemisphaerica, Alpinia galangal, Kaempferia galangal, Zingiber officinale, Zingiber cassumunar, and Curcuma domestica, 4 species that have geragih, namely Cyperus rotundus, Marsilea crenata, Fragaria vesca and Solanum tuberosum , 4 species that have tuber namely Ipomoea batatas, Colocasia esculenta, Cyperus rotundus, and Solanum tuberosum, 3 species that spina, namely Solanum torvum, Hylocereus costaricensis, and Mammillaria xanaea, 1 species that has a bulb namely Amaryllis fariegata and 1 species that has tuber namely Musa paradisiaca, and diversity index $\left(\mathrm{H}^{\prime}\right)$ is 1.284 categorized as medium diversity.

Keywords: Diversity, Stem Modification, Morphology

\section{PENDAHULUAN}

Lubuklinggau Timur 1 merupakan salah satu kecamatan yang terdiri dari delapan kelurahan yang berada di Kota Lubuklinggau Provinsi Sumatera Selatan dan memiliki luas wilayah sebesar $1390 \mathrm{~km}^{2}$. Lubuklinggau beriklim trofis basah dengan variasi curah hujan rata-rata antara 2000-2500 mm/tahun, dimana setiap tahun jarang sekali ditemukan bulan kering, suhu udara rata-rata di Lubuklinggau sebesar 270C dan mempunyai fluktuasi yang tidak terlalu tinggi, sehingga sepanjang tahun relatif sama. Kelembaban udara rata-rata tahunan adalah sebesar 14\%, hal ini menunjukan bahwa kelembaban udara di wilayah Lubuklinggau bukan merupakan faktor penghambat bagi pertumbuhan tanaman (Nawasis, 2011). Suhu udara merupakan salah satu faktor iklim yang sangat mempengaruhi tanaman. Mengingat variasi spasial dan temporal suhu udara di Indonesia tidak terlalu besar maka kajian tentang fenologi jarang dilakukan. Kajian perubahan iklim dan fenologi tanaman lebih banyak dilakukan di negara-negara subtropis karena variasi suhu udara secara spasial dan temporal sangat tinggi (Servina, 2019). Berdasarkan faktor iklim inilah Lubuklinggau memiliki keragaman Morfologi Modifikasi Batang (caulis).

Keanekaragaman tumbuhan dapat ditinjau dari struktur morfologinya, baik daun, batang, akar, bunga, dan organ modifikasi (Rosanti, 2013). Morfologi batang untuk vegetasi tingkat pohon dapat menjadi karakteristik arsitektur pohon, mulai 
dari pola pertumbuhan batang, cabang, dan ranting yang berbeda-beda. Hal ini dapat diartikan bahwa pohon-pohon tersebut memiliki model arsitektur pohon tertentu (Hasanuddin, 2013).

Batang merupakan bagian tubuh tumbuhan penting. Mengingat tempat serta kedudukan batang bagi tubuh tumbuhan, batang sering dikatakan sebagai sumbu tubuh tumbuhan. Batang sebagian besar tumbuhan terletak di permukaan tanah, namun ada pula batang yang terdapat di dalam tanah, bahkan ada tumbuhan yang tampak tidak berbatang (planta acaulis) walaupun sesungguhnya berbatang hanya sangat pendek sekali sehingga seolah-olah tidak berbatang (Haryani, 2012). Tumbuhtumbuhan yang tidak berbatang, sesungguhnya tidak ada, hanya tampaknya saja yang tidak ada. Hal ini disebabkan karena morfologi batang amat pendek sehingga semua daunnya seakan-akan keluar dari atas akarnya dan tersusunrapatsatu sama lain, atau karena batang tumbuhan tersebut bermetamorfosis/berubah bentuk (Tjitrosoepomo, 2012).

Setiap jenis pohon yang ada di sekitar lingkungan memiliki ciri yang khas dalam rangkaian proses pertumbuhannya yang diwariskan secara genetik (Hidayat et al. 2018). Aneka vegetasi yang mengandung nilai-nilai ilmiah dapat dijadikan sebagai sarana pendidikan dan penelitian mahasiswa, terutama dalam mempelajari pola percabangan pohon pada matakuliah morfologi tumbuhan. Tujuan dalam penelitian ini adalah untuk mengkaji keragaman morfologi modifikasi batang di Lubuklinggau.

\section{METODE}

Penelitian ini dilakukan di Lubuklinggau Timur 1, Kota Lubuklinggau, Sumatera Selatan. Metode pengambilan data dilakukan dengan cara menjelajah ke semua lahan dan pemukiman warga. Sampel yang diperoleh dicatat meliputi nama spesies, morfologi modifikasi batang (caulis) dan jumlah individu. Kegiatan identifikasi dipandu buku Tjitrosoepomo (2007) dan Steenis, et al. (2008).

Data yang diperoleh ditabulasi meliputi morfologi, modifikasi batang dan penamaan taksonomi spesies berdasarkan famili, genus, spesies dan jumlah individu. Analisis data menggunakan kerapatan relatif dan indeks keanekaragaman ShanonWhiener:

Rumus kerapatan jenis:

Keterangan:

$$
\mathrm{KR}=\mathrm{ni} / \mathrm{N} \times 100 \%
$$

ni = Jumlah individu dari suatu jenis

$\mathrm{N} \quad=$ Jumlah total individu seluruh jenis

$$
H^{\prime}=-\sum \frac{n i}{N} \log \frac{n i}{N}
$$

Keterangan:

$\mathrm{H}^{\prime} \quad=$ indeks keanekaragaman Shanon-Whiener

ni = Jumlah individu dari suatu jenis

$\mathrm{N} \quad=$ Jumlah total individu seluruh jenis

Besarnya indeks keanekaragaman adalah:

nilai $\mathrm{H}^{\prime}>3 \quad=$ Keanekaragamantinggi

nilai $\mathrm{H}^{\prime} 1 \leq \mathrm{H}^{\prime} \leq 3 \quad$ = Keanekaragaman sedang

nilai $H^{\prime}<1 \quad$ = Keanekaragaman rendah (Fachrul, 2012). 


\section{HASIL DAN PEMBAHASAN}

Berdasarkan Tabel 1 dapat terlihat bahwa setelah diadakan penelitian ditemukan 17 famili, 27 genus dan 29 species. Famili zingiberaceae merupakan famili yang terbanyak ditemukan karena banyak tumbuh di ladang dan halaman rumah masyarakat. Zingiberaceae adalah jenis tumbuhan temu-temuan, yang memiliki rimpang yang berbau khas. Tumbuhan dari suku Zingiberaceae sangat sering dijumpai di kawasan Indonesia, hal ini dikarenakan Indonesia beriklim tropis yang sangat sesuai untuk tumbuhnya berbagai jenis tumbuhan. Zingiberaceae banyak digunakan oleh etnis-etnis di Indonesia berdasarkan pengetahuan turun temurun, informasi dari tetangga atau media massa (Arum et al. 2012). Zingiberaceae merupakan famili dari tumbuhan herba merimpang dan beraroma yang terdapat di daerah tropis Asia dan terdiri genus meliputi atas 1.300 jenis tumbuhan. Sebagian besar jenis famili Zingiberaceae ditemukan sebagai tumbuhan teresterial di dataran rendah, namun juga ada juga yang ditemukan di pegunungan dan hidup sebagai epifit (Suhono \& Tim LIPI, 2010). Zingiberacae juga merupakan tumbuhan dasar dari hutan tropis yang banyak ditemukan tumbuh di tempat yang rindang dan lembab, kadangkadang di temukan di hutan sekunder. Beberapa jenis dapat bertahan hidup di tempat yang terbuka dan tumbuh pada kemiringan yang tinggi (Delta et al. 2013).

Berdasarkan Tabel 2, kerapatan relatif tertinggi adalah Cyperus rotundus (Teki) sebesar 28,37, hal ini disebabkan karena tanaman rumput teki (Cyperus rotundus) dapat tumbuh pada kondisi yang berbeda dari lahan pertanian, terutama pada lahan kering (Nihayati et al. 2016). Selan itu, menurut Pranasari, et al. (2012) rumput teki (Cyperus rotundus) adalah salah satu gulma yang penyebarannya luas dan hampir selalu ada di sekitar segala tanaman budidaya, karena mempunyai kemampuan tinggi untuk beradaptasi pada jenis tanah yang beragam. Sedangkan kerapatan relatif terendah adalah Vitis vinifera (Anggur) sebesar 0,068. Hal ini disebabkan karena tanaman anggur merupakan tanaman tahunan yang memerlukan cahaya matahari penuh sampai dengan naungan sebagian (USA Gardener, 2011). Nilai kerapatan relatif menandakan bahwa terdapat variasi mengenai kerapatan jenis yang ditemukan di Lubuklinggau Timur 1. Hal ini sesuai dengan hasil penelitian Gunawan, et al., (2011) yang menyatakan bahwa nilai kerapatan suatu jenis vegetasi menunjukkan jumlah individu jenis vegetasi bersangkutan pada satuan luas tertentu, maka nilai kerapatan merupakan gambaran mengenai jumlah jenis vegetasi tersebut pada masing-masing tipe ekosistem.

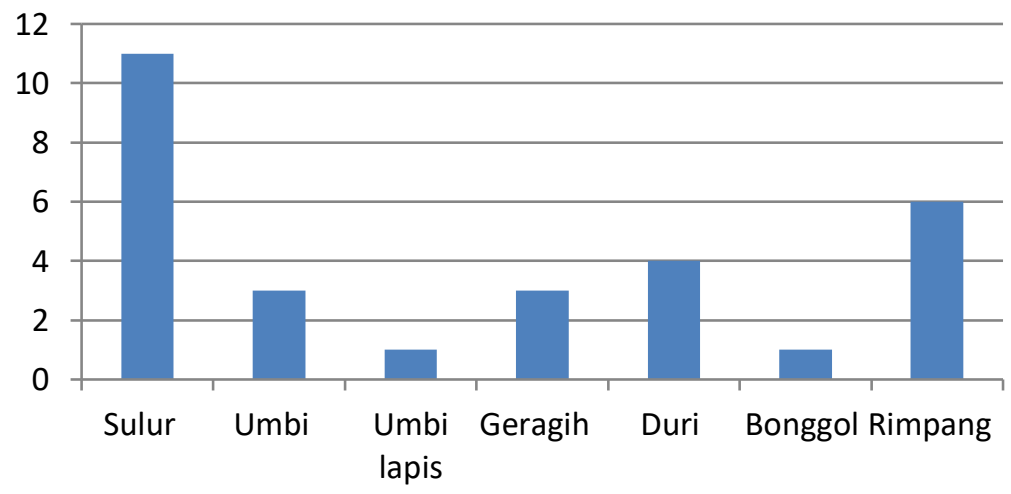

Gambar 1. Jumlah Tumbuhan Berdasarkan Modifikasi 
Tabel 1. Keanekaragaman Morfologi Modifikasi Batang (caulis) di Kecamatan Lubuklinggau Timur I

\begin{tabular}{|c|c|c|c|c|c|}
\hline No & Famili & Genus & Bahasa Indonesia & Bahasa Latin & $\begin{array}{c}\text { Nama Modifikasi } \\
\text { Batang }\end{array}$ \\
\hline 1 & & Pisum & Kacang Arcis & Pisum sativum & Sulur \\
\hline 2 & Fabaceae & Psophocarpus & Kecipir & $\begin{array}{l}\text { Psophocarpus } \\
\text { tetragonolobus }\end{array}$ & Sulur \\
\hline 3 & & Vigna & Kacang Panjang & Vigna sinensis & Sulur \\
\hline 4 & Convulvulaceae & Ipomoea & Ubi Jalar & Ipomoea batatas & Umbi, sulur \\
\hline 5 & Araceae & Colocasia & Keladi & Colocasia esculenta & Umbi \\
\hline 6 & Piperaceae & Piper & Sirih & Piper betle & Sulur \\
\hline 7 & Amaryllidaceae & Amaryllis & Bakung & Amaryllis fariegata & Umbi lapis \\
\hline 8 & Cyperaceae & Cyperus & Teki & Cyperus rotundus & $\begin{array}{l}\text { Umbi, Rimpang, } \\
\text { Geragih }\end{array}$ \\
\hline 9 & Marsileaceae & Marsilea & Semanggi & Marsilea crenata & Geragih \\
\hline 10 & Rosaideae & Fragaria & Strowberi & Fragaria vesca & Geragih \\
\hline 11 & Solanaceae & Solanum & Kentang & Solanum tuberosum & Geragih, Umbi \\
\hline 12 & & Solanum & Takokak & Solanum torvum & Duri \\
\hline 13 & & Cucumis & Timun & Cucumis sativus & Sulur \\
\hline 14 & & Momordica & Pare & Momordica charantia & Sulur \\
\hline 15 & Cucurbitaceae & Cucurbita & Labu & Cucurbita moschata & Sulur \\
\hline 16 & & Passiflora & Markisa & $\begin{array}{l}\text { Passiflora } \\
\text { quadrangularis }\end{array}$ & Sulur \\
\hline 17 & Aracaceae & Salacca & Salak & Salacca edulis & Duri \\
\hline 18 & Musaceae & Musa & Pisang & Musa paradisiaca & Bonggol \\
\hline 19 & Minispermaceae & Cylea & Cincau & Cylea barbata & Sulur \\
\hline 20 & Vitaceae & Vitis & Anggur & Vitis vinifera & Sulur \\
\hline 21 & Asteraceae & Mikania & Rayutan & Mikania micrantha & Sulur \\
\hline 22 & Cactaceae & Hylocereus & Naga & $\begin{array}{l}\text { Hylocereus } \\
\text { costaricensis }\end{array}$ & Duri \\
\hline 23 & & Mammillaria & Kaktus & Mammillaria xanaea & Duri \\
\hline 24 & & Etlingera & Kecombrang & $\begin{array}{l}\text { Etlingera } \\
\text { hemisphaerica }\end{array}$ & Rimpang \\
\hline 25 & & Alpinia & Languas & Alpinia galanga & Rimpang \\
\hline 26 & Zingiberaceae & Kaempferia & Kencur & Kaempferia galangal & Rimpang \\
\hline 27 & & Zingiber & Jahe & Zingiber officinale & Rimpang \\
\hline 28 & & Zingiber & Bengle & Zingiber cassumunar & Rimpang \\
\hline 29 & & Curcuma & Kunyit & Curcuma domestica & Rimpang \\
\hline
\end{tabular}

Dari Gambar 1, terlihat bahwa modifikasi batang terbanyak yaitu berupa sulur, ditemukan sebanyak 12 spesies yang memiliki sulur (cirrhus). Modifikasi batang terkecil yaitu Bonggol yaitu 1 species. Modifikasi batang berupa sulur antara lain: Kacang Arcis (Pisum sativum), Kecipir (Psophocarpus tetragonolobus), Kacang Panjang (Vigna sinensis), Ubi Jalar (Ipomoea batatas), Sirihv (Piper betle), Timunv (Cucumis sativus), Pare (Momordica charantia), Labu (Cucurbita moschata),Markisa (Passiflora quadrangularis), Cincau hijau (Cylea barbata), Anggur (Vitis vinifera), Rayutan (Mikania micrantha). Sulur (cirrhus) merupakan modifikasi batang dan 
cabang yang berbentuk spiral dan berfungsi untuk membelit benda-benda yang disentuhnya, untuk berpegangan pada waktu tumbuhan berusaha mendapatkan penunjang untuk dapat naik ke atas (Haryani, 2012).

Tabel 2. Data kerapatan Relatif dan Indeks Keanekaragaman Morfologi Modifikasi Batang (caulis) di Kecamatan Lubuklinggau Timur I

\begin{tabular}{|c|c|c|c|c|}
\hline No & Famili & Jumlah & KR & H \\
\hline 1 & Fabaceae & 19 & 0,651801 & \multirow{30}{*}{1,284} \\
\hline 2 & & 21 & 0,7204117 & \\
\hline 3 & & 52 & 1,7838765 & \\
\hline 4 & Convulvulaceae & 103 & 3,5334477 & \\
\hline 5 & Araceae & 95 & 3,2590051 & \\
\hline 6 & Piperaceae & 32 & 1,0977702 & \\
\hline 7 & Amaryllidaceae & 40 & 1,3722127 & \\
\hline 8 & Сyperaceae & 827 & 28,370497 & \\
\hline 9 & Marsileaceae & 83 & 2,8473413 & \\
\hline 10 & Rosaideae & 11 & 0,3773585 & \\
\hline 11 & Solanaceae & 4 & 0,1372213 & \\
\hline 12 & \multirow{5}{*}{ Cucurbitaceae } & 34 & 1,1663808 & \\
\hline 13 & & 10 & 0,3430532 & \\
\hline 14 & & 15 & 0,5145798 & \\
\hline 15 & & 5 & 0,1715266 & \\
\hline 16 & & 18 & 0,6174957 & \\
\hline 17 & Aracaceae & 3 & 0,102916 & \\
\hline 18 & Musaceae & 600 & 20,58319 & \\
\hline 19 & Minispermaceae & 4 & 0,1372213 & \\
\hline 20 & Vitaceae & 2 & 0,0686106 & \\
\hline 21 & Asteraceae & 130 & 4,4596913 & \\
\hline 22 & Cactaceae & 10 & 0,3430532 & \\
\hline 23 & \multirow{7}{*}{ Zingiberaceae } & 6 & 0,2058319 & \\
\hline 24 & & 6 & 0,2058319 & \\
\hline 25 & & 360 & 12,349914 & \\
\hline 26 & & 136 & 4,6655232 & \\
\hline 27 & & 59 & 2,0240137 & \\
\hline 28 & & 20 & 0,6861063 & \\
\hline 29 & & 210 & 7,2041166 & \\
\hline & Jumlah & 2915 & 100 & \\
\hline
\end{tabular}

Modifikasi batang rimpang (rhizoma) berjumlah 7 species yaitu Teki (Cyperus rotundus), Kecombrang (Etlingera hemisphaerica), Lengkuas (Alpinia galanga), Kencur (Kaempferia galanga), Jahe (Zingiber officinale), Bengle (Zingiber cassumunar), dan Kunyit (Curcuma domestica). Rimpang (Rhizoma), merupakan modifikasi batang yang terletak di dalam tanah, bercabang-cabang, dan tumbuh mendatar kesamping (Haryani 2012).

Modifikasi batang stolon (geragih) sebanyak 4 species yaitu Teki (Cyperus rotundus), Semanggi (Marsilea crenata), Strowberi (Fragaria vesca) dan Kentang 
(Solanum tuberosum). Stolon (Geragih) merupakan modifikasi batang yang tumbuh menyamping dan di ruang-ruasnya tumbuh bakal tanaman baru (Haryani, 2012).

Modifikasi batang Umbi batang (Tuber caulogenum) memiliki species 4 yaitu Ubi Jalar (Ipomoea batatas), Keladi (Colocasia esculenta), Teki (Cyperus rotundus), dan Kentang (Solanum tuberosum). Umbi batang (tuber caulogenum) merupakan modifikasi batang yang membengkak, bangun bulat seperti kerucut atau tidak beraturan dan merupakan tempat penimbunan makanan (Haryani, 2012).

Modifikasi batang duri (spina) memiliki 3 species yaitu Takokak (Solanum torvum), Naga (Hylocereus costaricensis), dan Kaktus (Mammillaria xanaea). Duri (spina) merupakan modifikasi dari batang dan daun, yang sukar ditanggalkan dari batang (Haryani, 2012).

Modifikasi batang yang paling sedikit ditemukan adalah umbi lapis (bulbus) dan bonggol umbi (cormus). Masing-masing hanya ditemukan 1 species, yaitu Bakung (Amaryllis fariegata) dan Pisang (Musa paradisiaca). Umbi lapis (bulbus) merupakan modifikasi batang dan daun yang berlapis-lapis. Dikatakan umbi lapis karena struktur susunannya yang berlapis-lapis (Haryani, 2012).Bonggol merupakan modifikasi pangkal batang yang berbentuk batang bulat pendek yang berada tepat di bawah permukaan tanah. Bonggol yang memiliki fungsi tambahan sebagai tempat cadangan energy (Haryani, 2012).

Berdasarkan tabel.1 dapat terlihat bahwa indeks keanekaragaman $\left(\mathrm{H}^{\prime}\right)$ morfologi modifikasi batang (caulis) di Kecamatan Lubuklinggau Timur 1 dari 29 spesies yang ditemukan adalah 1,284. Hal ini menunjukkan bahwa keanekaragaman morfologi modifikasi batang (caulis) di Kecamatan Lubuklinggau Timur I dalam kategori sedang. keanekaragaman morfologi modifikasi batang (caulis) di Kecamatan Lubuklinggau Timur 1 bisa disebabkan karena species yang ada memang hidup pada daerah yang sesuai untuk kelangsungan hidup species di Kecamatan Lubuklinggau Timur I.

\section{SIMPULAN}

Berdasarkan hasil penelitian tentang keragaman morfologi modifikasi batang (caulis) di Kecamatan Lubuklinggau Timur 1, maka dapat disimpulkan bahwa terdapat 29 spesies dengan 12 spesies yang memiliki sulur (cirrhus), 7 species yang memiliki rimpang (rhizoma), 3 species yang memiliki stolon (geragih), 4 species yang memiliki umbi batang (uber caulogenum), 3 species yang memiliki duri (spina), 1 species yang memiliki umbi lapis (bulbus), 1 species yang memiliki bonggol umbi (cormus). Indeks keanekaragaman tumbuhan modifikasi batang berkategori sedang.

\section{UCAPAN TERIMA KASIH}

Ucapan terima kasih terhadap pihak STKIP-PGRI Lubuklinggau yang telah memberikan dana penelitian, sehingga penelitian ini dapat terlaksana dengan baik dan lancar.

\section{REFERENSI}

Arum, GPF, Retnoningsih A, Irsadi A. (2012). Etnobotani Tumbuhan Obat Masyarakat Desa Keseneng Kabupaten Semarang Jawa Tengah Kecamatan Sumowono. Unnes Journal of Life Science 1 (2),126-132

Delta, A.M. Arbain A. Syamsuardi. (2013). Studi Jenis-jenis Zingiberaceae di Kawasan Hutan Lindung Gunung Talang Sumatera Barat. Jurnal Biologi Universitas Andalas, 2(3), 161-168.

Fachrul, M.F. (2012). Metode Sampling Bioekologi. Jakarta: Bumi Aksara. 
Gunawan, W., Basuni, S., Indrawan, A., Prasetyo, L.B. \& Soedjito, H. (2011). Analisis Komposisi dan Struktur Vegetasi Terhadap Upaya Restorasi Kawasan Hutan Taman Nasional Gunung Gede Pangrango. Jurnal Pengelolaan Sumber Daya Alam dan Lingkungan, 1(2), 93-105

Haryani, T.S. (2012). Organo Nutritivum (daun, batang dan akar). http://www.pustaka.ut.ac.id/lib/wp-content/uploads/pdfmk/PEBI4312-M1.pdf.

Retrieved Januari 122020.

Hasanuddin. (2013). Model Arsitektur Pohon Hutan Kota Banda Aceh Sebagai Penunjang Praktikum Morfologi Tumbuhan. Jurnal EduBio Tropika, 1(1), 3844.

Hidayat, M., Pratiwi O., Sartinawati R., Sakti VR. (2018). Stratifikasi dan Model Arsitektur Pohon Di Kawasan Hutan Sekunder Pegunungan Deudap Pulo Aceh Kabupaten Aceh Besar. Prosiding Seminar Nasional Biotik 2018.

Nawasis. (2011). Perencanaan Sanitasi. Lubuklingau: PPSP

Nihayati, E., Karyawati, A.S., Puspasari, D.L., \& Aziziah, N. (2016). Studi Potensi Alelopati Ekstrak Rimpang Temulawak (Curcuma xanthorriza Roxb.) Pada Rumput Teki (Cyperus rotundus) dan Perkecambahan Kedelai (Glycine max). Jurnal Agro, 3 (2), 43-52.

Pranasari, R. A., T. Nurhidayat, dan K. I. Pruwani. (2012). Persaingan Tanaman Jagung (Zea mays) dan Rumput Teki (Cyperus rotundus) pada Pengaruh Cekaman Garam (NaCl). Jurnal Sains dan Seni ITS, 1(1), 54-57.

Rosanti, D. (2013). Morfologi Tumbuhan. Jakarta: Erlangga.

Servina, Y. (2019). Dampak Perubahan Iklim dan Strategi Adaptasi Tanaman Buah dan Sayuran di Daerah Tropis. Jurnal Penelitian dan Pengembangan Pertanian, 38(2), 65-76.

Steenis, van C.G.G.J., G. den Hoed, P.J. Eyma. (2008). Flora, Cetakan ke-12. Jakarta: PT. Pradnya Paramita.

Suhono, B. dan Tim LIPI. (2010). Ensiklopedia Flora jilid 2. Bogor: PT. Kharisma Ilmu. LIPI

Tjitrosoepomo, G. (2007). Taksonomi tumbuhan (Spermatophyta). Yogyakarta: Gadjah Mada University Press.

Tjitrosoepomo, G. (2012). Morfologi Tumbuhan. Yogyakarta: Gadjah Mada University Press.

USA Gardener. (2011). Grapes: How to grow grapes. http://usagardener.com/how to grow fruits/how to grow grapes.php. Retrieved June 142019. 